\title{
IRON AND ZINC STATUS IN CHILDREN WITH SHORT STATURE
}

\author{
By \\ ${ }^{1}$ El Okda E, ${ }^{1}$ Abdel-Hamid MA, ${ }^{2}$ Gadalla F and ${ }^{2}$ Sabry I \\ ${ }^{1}$ Department of Community, Environmental and Occupational Medicine,${ }^{2}$ Department of Internal Medicine,
} Faculty of Medicine, Ain Shams University, Cairo, Egypt

\begin{abstract}
:
Introduction: Micronutrient deficiencies are prevalent in infancy and childhood where there is rapid growth and a concomitant high nutritional demand, particularly in developing countries. Other vulnerable periods are adolescence and pregnancy. Among micronutrients, iron is the most common nutritional deficiency in the world and is the major cause of anemia. Aim of work: The aim of this work was to study iron and zinc status among 12-16 years children with short stature for age. Materials and Methods: A case-control study was conducted including forty 12-16 years children (20 cases and 20 controls). Cases were children with short stature for age, attending the outpatient clinic of endocrinology department at Ain Shams University Hospitals (20 children). Controls were matched group selected from normal height-for-age children attending the outpatient clinic for another cause according to the inclusion criteria. All children were subjected to full laboratory assessment of serum iron and zinc in addition to complete blood picture and stool analysis. Socio-demographic, family and developmental histories were taken in addition to physical examination including height, weight, and secondary sexual characteristics. Results: The mean serum iron, serum ferritin and serum zinc level were significantly lower among cases than controls $(61.5 \pm 3.65$, $24.5 \pm 2.36$ and $54.3 \pm 5.65$ versus $66.8 \pm 4.32,32.5 \pm 5.32$ and $70.6 \pm 6.22$ respectively). Regarding Total Iron Binding Capacity (TIBC); the mean values were 325.6 \pm 109.58 among cases compared to $198.6 \pm 56.8$ among controls with statistically significant difference between them $(\mathrm{p}<0.05)$. There were significant positive correlations between serum iron level, serum ferritin and serum zinc level versus hemoglobin concentration and WBCs count. However, there was a significant negative correlation between iron binding capacity of stunted children and their hemoglobin concentration and WBCs count. There was no statistically significant correlations between them and weight or height of stunted children. Males had higher hemoglobin concentration, RBCs count and serum iron level compared to females $(11.5 \pm 1.4,3.8 \pm 0.9$ and $65 \pm 3$ compared to
\end{abstract}


$10 \pm 1.2,3.2 \pm 0.7,60.5 \pm 4$ respectively). Conclusion: Serum iron and serum zinc levels significantly decreased in children with short stature compared to normal children and their levels had positive linear correlation with hemoglobin concentration and WBCs count.

Keywords: Short Stature, Stunted Children, Serum Iron, Serum Zinc, Hemoglobin Concentration, Total Iron Binding Capacity (TIBC).

\section{Introduction}

The past few years have seen several substantial advances in our understanding of the importance of micronutrients in child health nutrition. Although, historically child nutrition in developing countries has focused on protein and energy sufficiency, more recent efforts have been made to evaluate and eliminate micronutrient deficiencies (Hendler and Rorvik, 2008). Micronutrient deficiencies are prevalent in during infancy and childhood, particularly in developing countries, when there is rapid growth and a concomitant high nutritional demand. Other vulnerable periods are adolescence and pregnancy. Among Micronutrients, iron is the most common nutritional deficiency and is the major cause of anemia (International Zinc Nutrition Consultative Group et al., 2004).

Iron is an absolute requirement for most forms of life, including humans and most bacterial species. Because plants and animals all use iron, iron can be found in a wide variety of food sources. It is essential to life because of its unique ability to serve as both an electron donor and acceptor. Iron can also be potentially toxic. Its ability to donate and accept electrons means that if iron is free within the cell, it can catalyze the conversion of hydrogen peroxide into free radicals. Free radicals can cause damage to a wide variety of cellular structures, and ultimately kill the cell (Crichton et al., 2002). Another micronutrient of concern is zinc. Despite of the lack of reliable markers as one of the main limitations of accurately determining the prevalence of zinc deficiency, evidence from supplementation studies and community-based investigations suggest that zinc deficiency can be as common as iron deficiency (CastilloDuran and Ruz, 2004). Zinc is one of the essential trace elements and, a member of one of the major subgroups of the micronutrients that have attained such prominence in human nutrition 
and health. Even a partial understanding of the fundamental importance of zinc in cellular growth and differentiation alerts us to the special vulnerability to an inadequate supply of zinc of the rapidly growing embryo, fetus, infant and young child (Hambidge, 2000). Zinc is essential for synthesis of coenzymes that mediate biogenic-amine synthesis and metabolism. Hence, Zinc is essential for brain development and function (Sandstead, 2003). The impact of zinc on growth was first described in humans in adolescent populations in Iran and Egypt. In these studies, young adults was presented with a syndrome characterized by varying degrees of growth stunting and delayed sexual maturation (hypogonadal dwarfism) (Henwood and Binkovitz, 2009).

\section{Aim of the Work}

To study iron and zinc status among 12-16 years children with short stature for age.

\section{Material and Methods}

\section{Study design and time:}

A case-control study was conducted from April 2014 till October 2014.

\section{Study population and setting:}

The study population consisted of 12-16 years old children free from chronic diseases like diabetes and cardiovascular diseases.

According to the height-for-age index, cases were children with short stature for age attending the outpatient clinic of endocrinology department at Ain Shams University Hospital. Controls were matched group of normal height-for-age attending the outpatient clinic for another cause.

The height-for-age index provides an indicator of linear growth. Children whose height-for-age measures are below minus two standard deviations (-2 SD) from the median of the reference population are considered short for their age, or stunted (WHO, 1995).

Accordingly, a systematic random sample of 40 children was selected from hospital records (20 cases and 20 controls).

Sample size was calculated guided by $95 \%$ confidence, $80 \%$ power and an accepted margin of error of $5 \%$. The following formula was used for sample size calculation:

$$
\mathrm{N}=\underline{2(\mathrm{SD})^{2} \times \mathrm{f}(\alpha, \beta) \text { where }}
$$

$\mathrm{D}^{2}$ 
$\mathrm{N}=$ required sample size per group

$\mathrm{SD}=$ standard deviation of measure

$\mathrm{f}=\mathrm{a}$ factor corresponding to the specified

$\alpha$ and $\beta$ error $($ function table $)=7.9$

$\mathrm{D}=$ the least significant difference (Hamburg, 1985)

\section{Study methods:}

All participants enrolled in the study were subjected to the following:

1. A predesigned interviewed questionnaire including data about socio-demographic, dietary, developmental and family history.

2. Complete Clinical examination with stress on the height, weight, and Secondary sexual characters,

3. Laboratory Investigations including stool analysis, complete blood count (CBC), and measurement of iron and zinc level with atomic absorption technique.

Blood samples, were collected in the morning, it consisted of plasma centrifuged from full circular blood.

\section{- Iron Concentration:}

Reference Value: Serum Iron (SI): Children: 50 to $120 \mu \mathrm{g} / \mathrm{dL}$ (Ginder, 2011).
Procedure: Iron concentration was determined by colorimetry with bath of phenanthroline. Transferrin-bound iron was released using sodium dodecyl sulphate (SDS) and reduced to Fe2+ using hydroxylamine (Skrzypczak et al., 2009). The reagent samples were incubated at $37^{\circ} \mathrm{C}$ for $20 \mathrm{~min}$. The absorbance read reagent sample at the wave length $\lambda=535 \mathrm{~nm}$. Iron concentrations in the plasma were read from the calibration curve (Lai, 2012).

\section{- Zn concentration (Zinc assay Kit):}

Reference Values: reference range $\geq 11$ years: $0.66-1.10 \mathrm{mcg} / \mathrm{mL}$ i.e. (60-120 $\mu \mathrm{g} / \mathrm{dL})$ Procedure: Three (3) samples of acidified zinc solutions were provided for analysis, labeled A, $\mathrm{B}$ and $\mathrm{C}$. The concentrations of each solution were provided by two methods; Titrimetry and Flame atomic absorption spectrometry, to ensure the accuracy of the generated results.

\section{- Serum Ferritin:}

Ferritin is primarily an intracellular molecule that stores iron in a form that is readily accessible to the cell. The functional molecule, which is composed of 24 chains, is roughly spherical and 
contains a central cavity into which the polymeric ferric iron core is deposited. Serum ferritin is easily measured using an inexpensive and commercially available kit. Repeated measurements of serum ferritin levels can be easily carried out to allow regular monitoring (Jensen, 2004).

Normal ranges of serum ferritin: The ranges for ferritin can vary between laboratories but are usually between $30-300 \mathrm{ng} / \mathrm{mL} \quad(=\mu \mathrm{g} / \mathrm{L})$ for males, and $6-115 \mathrm{ng} / \mathrm{mL}(=\mu \mathrm{g} / \mathrm{L})$ for females (Ginder, 2011). The range in children (above 6 months) is 7-140 ng/ $\mathrm{mL}$.

\section{- Total iron binding capacity (TIBC):}

TIBC is a medical laboratory test that measures the blood's capacity to bind iron with transferrin. It is performed by drawing blood and measuring the maximum amount of iron that it can carry, which indirectly measures transferrin since transferrin is the most dynamic carrier. TIBC is less expensive than a direct measurement of transferrin (Yamanishi et al., 2003).

Normal Results: TIBC: 240-450 mcg/dL and Transferrin saturation: 2050\% (Ginder, 2011).

\section{Data management:}

Data entry and statistical analysis were performed using SPSS program version 20.The data collected were analyzed by descriptive as well as inferential analysis. The significance level was set at $\mathrm{P}<0.05$.

\section{Consent}

Authors declare that a verbal consent was taken from the studied groups before starting the research work. Confidentiality was maintained.

\section{Ethical approval}

The study protocol was approved by Community, Environmental and Occupational Medicine, and Internal Medicine Ethical committee, Faculty of Medicine, Ain Shams University, Cairo. 


\section{Results}

Table 1: Socio-Demographic and Personal Characteristics of the Participating Groups

\begin{tabular}{|l|c|c|c|c|}
\hline Characteristics & $\begin{array}{c}\text { Cases } \\
\mathrm{N}=20\end{array}$ & $\begin{array}{c}\text { Controls } \\
\mathrm{N}=20\end{array}$ & $\begin{array}{c}\text { Test of } \\
\text { Significance }\end{array}$ & p-value \\
\hline Age & $13.6 \pm 1.8$ & $14.6 \pm 1.9$ & $\mathrm{t}=0.7$ & 0.44 \\
\hline $\begin{array}{l}\text { Gender } \\
\text { Male n (\%) }\end{array}$ & $10(50 \%)$ & $11(55 \%)$ & $\mathrm{X}^{2}=0.42$ & 0.61 \\
Female n (\%) & $10(50 \%)$ & $9(45 \%)$ & & \\
\hline Height Mean \pm SD & $128 \pm 8.9$ & $136.8 \pm 7.0$ & $\mathrm{t}=2.6^{*}$ & 0.04 \\
\hline Weight Mean $\pm \mathrm{SD}$ & $60.2 \pm 8.0$ & $68.7 \pm 9.0$ & $\mathrm{t}=2.5^{*}$ & 0.05 \\
\hline
\end{tabular}

*The difference is significant at 0.05 level

Table 1 show that there is no significant difference between both groups ( $p$ $>0.05$ ) on comparing the mean age. There was also no statistically significant difference in gender between both groups.

Regarding the anthropometric measurements; the height and the weight were lower among cases compared to the controls with significant difference between them $(\mathrm{p}<0.05)$.

Table 2: Comparison between Dietary Histories of the Participating Groups

\begin{tabular}{|l|c|c|c|c|}
\hline Number of serving/week & $\begin{array}{c}\text { Cases } \\
\mathrm{N}=20\end{array}$ & $\begin{array}{c}\text { Controls } \\
\mathrm{N}=20\end{array}$ & $\mathbf{t}$ & p-value \\
\hline Cereals intake & $5.0 \pm 2.0$ & $3.0 \pm 1.2$ & $2.2^{*}$ & 0.03 \\
\hline Red meat & $1.0 \pm 0.5$ & $3.0 \pm 0.4$ & $2.4^{*}$ & 0.04 \\
\hline Poultry & $1.0 \pm 0.2$ & $2.0 \pm 0.3$ & 1.4 & 0.32 \\
\hline Fish & $1.0 \pm 0.3$ & $2.0 \pm 0.6$ & 1.5 & 0.22 \\
\hline Egg & $3.0 \pm 1.2$ & $5.0 \pm 2.0$ & $2.9^{*}$ & 0.02 \\
\hline Dairy products & $2.0 \pm 0.5$ & $4.0 \pm 1.4$ & $3^{* *}$ & 0.002 \\
\hline Bread & $7.0+2.2$ & $5.0+2.1$ & $2.3^{*}$ & 0.04 \\
\hline Fresh vegetables & $5.0 \pm 2.2$ & $3.0 \pm 1.0$ & $2.1^{*}$ & 0.05 \\
\hline Fresh fruits & $3.0 \pm 1.9$ & $5.0 \pm 1.5$ & $1.9^{*}$ & 0.11 \\
\hline Chips and similar snacks & $7.0+2.1$ & $4.0+1.1$ & $2.5^{*}$ & 0.04 \\
\hline Soft drinks & $2.0 \pm 0.5$ & $3.0 \pm 1.1$ & 1.4 & 0.20 \\
\hline
\end{tabular}

*The difference is significant at 0.05 level

**The difference is significant at 0.01 level

\# Mann-Whitney test 
Table 2 shows that the average consumption of red meat, egg and dairy products among stunted cases were lower compared to controls with statistically significant differences between them. On the other hand, the intake of cereals, bread, fresh vegetables and chips and similar snacks among stunted cases were higher compared to controls with statistically significant differences between them. There were no statistically significant differences between both groups regarding consumption of poultry, fish, fresh fruits and soft drinks.

Table 3: Comparison between Stool Analysis Results of the Participating Groups

\begin{tabular}{|l|c|c|c|}
\hline Stool analysis for parasitic infestation & $\begin{array}{c}\text { Cases } \\
\mathrm{N}=20\end{array}$ & $\begin{array}{c}\text { Controls } \\
\mathrm{N}=20\end{array}$ & \multirow{2}{*}{ p-value } \\
\cline { 1 - 3 } Negative & $17(85 \%)$ & $18(90 \%)$ & \multirow{2}{*}{$0.71 \mathrm{NS}^{*}$} \\
\cline { 1 - 3 } Positive & $3(15 \%)$ & $2(10 \%)$ & \\
\hline
\end{tabular}

* Fisher exact

Table 3 shows that 2 cases had positive parasitic infection among control group, while 3 cases show positive results in study group, with no significant difference between both groups regarding the stool analysis $(\mathrm{p}>0.05)$.

\section{Table 4: Comparison between Laboratory Data of the Participating Groups}

\begin{tabular}{|l|c|c|c|c|}
\hline Lab. Data & $\begin{array}{c}\text { Cases } \\
\mathrm{N}=20\end{array}$ & $\begin{array}{c}\text { Controls } \\
\mathrm{N}=20\end{array}$ & $\mathbf{t}$ & $\mathbf{P}$ \\
\hline Hb conc. & $10.01+1$ & $11.15+0.98$ & $2.6^{*}$ & 0.03 \\
\hline WBCs & $5.36 \pm 0.71$ & $5.82 \pm 0.69$ & 1.4 & 0.31 \\
\hline RBCs & $3.2 \pm 0.61$ & $3.7 \pm 0.41$ & $2.7^{*}$ & 0.048 \\
\hline Serum iron (ug/dl) & $61.5 \pm 3.65$ & $66.8 \pm 4.32$ & $2.9^{*}$ & 0.042 \\
\hline Serum ferritin (ng/ml) & $24.5 \pm 2.36$ & $32.5 \pm 5.32$ & $2.5^{*}$ & 0.03 \\
\hline TIBC & $325.6 \pm 109.58$ & $198.6 \pm 56.8$ & $3.2^{* *}$ & 0.0001 \\
\hline Serum zinc (mg/dl) & $54.3 \pm 5.65$ & $70.6 \pm 6.22$ & $3^{* *}$ & 0.001 \\
\hline
\end{tabular}

*The difference is significant at 0.05 level

$* *$ The difference is significant at 0.01 level

TIBC: Total Iron Binding Capacity 
Table 4 shows that, mean HB concentration and RBCs count , serum iron, serum ferritin TIBC and serum zinc were higher among controls when compared to cases with statistically significant difference $(\mathrm{p}<0.05)$. The mean WBCs count was $5.82 \pm 0.69$ among controls, compared to $5.36 \pm 0.71$ among cases with no statistically significant difference.

Table 5: Correlation between Serum Zinc, Iron, Ferritin and TIBC versus different Studied Parameters among Cases

\begin{tabular}{|l|c|c|c|c|c|c|c|c|}
\hline & \multicolumn{2}{|c|}{$\begin{array}{c}\text { Serum iron } \\
\text { level }\end{array}$} & \multicolumn{2}{c|}{$\begin{array}{c}\text { Iron binding } \\
\text { capacity }\end{array}$} & \multicolumn{2}{c|}{ Serum ferritin } & \multicolumn{2}{c|}{ Serum zinc } \\
\cline { 2 - 10 } & $\mathrm{r}$ & $\mathrm{p}$ & $\mathrm{r}$ & $\mathrm{p}$ & $\mathrm{r}$ & $\mathrm{p}$ & $\mathrm{r}$ & $\mathrm{p}$ \\
\hline Hb conc. & $0.91^{*}$ & 0.001 & $0.96^{*}$ & 0.001 & $-0.95^{*}$ & 0.001 & $0.90^{*}$ & 0.001 \\
\hline WBCs & $0.96^{*}$ & 0.001 & $0.70^{*}$ & 0.001 & $-0.92^{*}$ & 0.001 & $0.76^{*}$ & 0.001 \\
\hline Weight & 0.37 & 0.201 & 0.12 & 0.41 & 0.13 & 0.32 & 0.20 & 0.31 \\
\hline Height & 0.37 & 0.15 & 0.23 & 0.42 & 0.21 & 0.33 & 0.11 & 0.43 \\
\hline
\end{tabular}

* Correlation is significant at 0.01 levels (2-tailed).

Table 5 shows that there was a significant positive correlation between serum iron level versus hemoglobin concentration and WBCs count $(\mathrm{r}=0.91$ and 0.96 respectively), while there was no statistically significant correlations between it with weight or height of stunted children $(\mathrm{p}>0.05)$.

There was a significant negative correlation between iron binding capacity of stunted children with their hemoglobin concentration and WBCs count $(r=-0.95$ and -0.92 respectively). However, there was no correlation between it and weight or height $(\mathrm{p}>0.05)$ of stunted children.

There was a significant positive correlation between serum ferritin versus hemoglobin concentration and WBCs count ( $r=0.96$ and 0.70 respectively), while there was no statistically significant correlations between it with weight or height of stunted children $(\mathrm{p}>0.05)$. 
There was a significant positive correlation between serum zinc level versus hemoglobin concentration and WBCs count $(\mathrm{r}=0.90$ and 0.76 respectively), while there was no statistically significant correlations between it with weight or height of stunted children $(\mathrm{p}>0.05)$.

Table 6: Comparison between Laboratory Data of Male versus Female Cases

\begin{tabular}{|l|c|c|c|c|}
\hline Variables & $\begin{array}{c}\text { Males } \\
\mathbf{N = 1 0}\end{array}$ & $\begin{array}{c}\text { Females } \\
\mathbf{N = 1 0}\end{array}$ & $\mathbf{t}$ & p-value \\
\hline HB(gm/dl) & $11.5 \pm 1.4$ & $10 \pm 1.2$ & $2.7 *$ & 0.02 \\
\hline WBCs & $5.7 \pm 0.8$ & $5.5 \pm 0.70$ & 0.9 & 0.71 \\
\hline RBCs & $3.8 \pm 0.9$ & $3.2 \pm 0.7$ & $2.8 *$ & 0.03 \\
\hline Serum iron (ug/dl) & $65 \pm 3$ & $60.5 \pm 4$ & $3 * *$ & 0.002 \\
\hline Serum ferritin (ng/ml) & $32.7 \pm 6$ & $30 \pm 3$ & 1.9 & 0.11 \\
\hline TIBC & $300 \pm 60$ & $320 \pm 100$ & 1.3 & 0.23 \\
\hline Serum zinc (mg/dl) & $54 \pm 5$ & $50 \pm 6$ & 1.5 & 0.21 \\
\hline
\end{tabular}

*The difference is significant at 0.05 level

**The difference is significant at 0.01 level

TIBC: Total Iron Binding Capacity

Table 6 shows that males had higher hemoglobin concentration, RBCs count and serum iron compared to females .On the other hand, there was no significant difference between males and females as regard other variables $(p>0.05)$. 


\section{Discussion}

Stunting is a process that can affect the development of children from the early stages of conception until the third or fourth year of life, when the nutrition of the mother and the child are essential determinants of growth. Failure to meet micronutrient requirements, a challenging environment and the inadequate provision of care, are all factors responsible for this condition that affects almost 200 million children under 5 years of age (Branca and Ferrari, 2002).

This study was carried out on 40 subjects, twenty of them were suffering from short stature for age (cases) and the other twenty children were normal stature for age according to height-forage growth chart (control). Both groups were matched by age and gender thus there were no statistically significant difference between them regarding age and gender.

Regarding the anthropometric measurements of children in both groups, the weight appears to be lower among cases and not only their height with statistically significant difference. These findings were in agreement with a study by Madan et al. (2011) who found that weight and height in study patients (short stature) were lower than control group, thus they commented that delayed development in short stature children was not including only the height but extended to weight also. This finding may be explained by environmental and nutritional factors that play apparent rule in limitation of the normal growth process.

Regarding the nutritional history of the study groups; stunted cases were found to have lower intake of animal proteins (red meat, egg and dairy products) compared to controls. On the other hand, stunted children had higher intake of cereals, bread, fresh vegetables and chips and similar snacks than controls which reflect the high carbohydrate and low protein diet of stunted cases compared to controls. The micronutrient density of such diet is low, and the high phytate content impairs micronutrient absorption, resulting in a high risk of inadequacy of micronutrients like zinc and iron. These findings are consistent with a study by Friis et al. (1997) among Zimbabwean school children; they found that stunted children were malnourished and that they had high carbohydrate and cereals diet replacing balanced diet. 
Results revealed that there was no statistically significant difference between both groups regarding the stool analysis results. This finding may exclude that parasitic infestation is the cause of short stature in the studied group. In agreement with this study, Nwosu and Lee (2008) found that GIT diseases, especially malabsorption and malnutrition were the commonest chronic problems causing short stature in their study.

The mean hemoglobin concentration and RBCs count were significantly lower in short stature cases than in control group. This finding may be explained by the lower serum iron level which is the key part of hemoglobin and RBCs among those cases.

In addition to the lower serum iron level, serum ferritin and zinc levels were also significantly lower among stunted cases compared to controls. On the other hand, TIBC was significantly higher among stunted cases compared to controls. These results agree with the study of Perrone et al. (1999), who found that ferritin and serum, erythrocyte and hair zinc contents were significantly lower in short stature children than in age-matched controls. They also found that Iron plus Zinc supplementation caused an improvement in growth rate in all subjects. Another study by Kodama (2004) revealed that $60 \%$ of short-statured children without any endocrine disease were found to have zinc deficiency, and zinc administration was associated with an increase of body height. On the other hand, Sachdev et al. (2006), who performed a systematic review of randomized controlled trials (RCTs), did not document a positive effect of iron supplementation on the physical growth of children.

Anderson et al. (2004) study the effect of zinc on nutritional and biochemical parameters among children aged 12 to 59 months. Baseline serum zinc levels were low in stunted groups.

Zinc and iron are considered very important micronutrients that could change not only the physical and anthropometric status but also mental and physiological status, as zinc is essential for more than 300 enzyme activities. Stunting and poor growth are considered one of the most striking problem among children. This conclusion is supported by several clinical trials which study the effect of zinc and iron supplementation 
on physical growth. Perrone et al. (1999) in their study found that zinc supplementation significantly improved growth (weigh-for-age $\mathrm{Z}$ score (WAZ) and knee-heel length), and that iron supplementation significantly improved knee-heel length and psychomotor development compared with placebo. A meta-analysis of 33 randomized intervention trials showed that zinc supplementation produced highly significant positive response in weight gain as well as linear growth (Brown et al., 2002).

Serum iron, ferritin and zinc levels were positively correlated with hemoglobin concentration. This finding reflects the possible synergistic effect of zinc in case of anemia. Iron deficiency anemia was the most prevalent non communicable disease among children in Egypt, this means that any management of iron deficiency anemia shall include additional trace like zinc supplementation. These results was supported by the results of Allen (2008), it included a trial for micronutrients and zinc supplementation. His study revealed that there was a direct correlation detected between iron and zinc versus blood indices.
Serum iron, ferritin and zinc levels were also positively correlated with WBCs count. This finding reflects the direct relation between these trace elements and the immune status of the studied children. A vicious circle may occur due to malnutrition that leads to impaired immune response to the common infections in addition to other non-communicable diseases like cancer. The resulting infections may in turn lead to malabsorption and increase the severity of malnutrition. This finding agrees with a study by Hettiarachchi et al. (2008) which proved the efficiency of zinc and iron supplementation on the immune status among children in Sirilanka.

On the other hand, there was no correlation between serum iron level, serum ferritin and serum zinc levels of stunted children and their anthropometric measurement. These results agree with a study of Amare et al. (2012) who found that, although serum iron and zinc were statistically lower in stunted children than in control group, no statistically significant linear correlation was detected between either zinc or iron versus anthropometric measures of stunted patients. This may 
be explained by the fact that physical growth of children represented by their weight and height is not only related to the micronutrients but is multifactorial in origin and many other factors may play a role. No statistically significant difference was detected between males and females regarding serum zinc and iron levels ( $p>0.05)$.

\section{Conclusion}

Serum iron and zinc levels were significantly decreased in stunted children compared to normal children and their levels had positive linear correlation with hemoglobin concentration and WBCs count.

\section{Recommendations}

According to the results of the current study, it is recommended to:

Develop a national program for supplementation of not only iron but also zinc for school children

Develop a health education campaign for awareness of the importance of micronutrients especially iron and zinc for prevention of short stature

\section{Conflict of interests}

Authors have declared that no conflict of interests exists.

\section{References}

1. Anderson LJ, Westwood MA, Holden S et al. (2004): Myocardial iron clearance during reversal of siderotic cardiomyopathy with intravenous desferrioxamine: a prospective study using T2 cardiovascular magnetic resonance. Br J Haematol ;127(3):348-55.

2. Allen LH (2008): Zinc and micronutrient supplements for children. Am J Clin Nutr; 68 (495S-498S)53:245-50.

3. Amare B, Moges B, Fantahun B et al. (2012): Micronutrient levels and nutritional status of school children living in Northwest Ethiopia. Nutrition Journal; 11:108. Available at: http://www.nutritionj.com/content/11/1/108 (Retrieved 16 November 2014).

4. Brown KH, Peerson JM, Rivera J and Allen LH (2002): Effect of supplemental zinc on the growth and serum zinc concentrations of pre-pubertal children: a meta-analysis of randomized controlled trials. Am J Clin Nutr; 75(6): 1062-71.

5. Branca F and Ferrari M (2002): Impact of Micronutrient Deficiencies on Growth: The Stunting Syndrome. Ann Nutr Metab; 46(1):817.

6. Castillo-Duran C and Ruz M (2004): Epidemiology of micronutrient deficiencies in developing and developed countries, specifically zinc, copper, selenium and iodine. In Micronutrient Deficiencies during the Weaning Period and First Years of Life. Nestlé Nutrition Workshop Series, Pediatric Program, Vol. 54.Pettifor JM and Zlotkin S. (editor). pp. 37-52.

7. Crichton RR, Wilmet S, Legsyer R and Ward RJ (2002): Molecular and cellular mechanisms of iron homeostasis and toxicity in mammalian cells. J Inorg Biochem ; 91: 9-18.

8. Friis H, Ndhlovu P, Mduluza T et al. (1997): The impact of zinc supplementation on growth and body composition: a randomized, controlled trial among rural Zimbabwean schoolchildren. Eur J Clin Nutr ;51(1): 38-45. 
9. Ginder GD (2011): Microcytic and hypochromic anemia. In: Goldman L, Schafer AI, eds. Goldman's Cecil Medicine. 24th ed. Philadelphia, Pa: Elsevier Saunders; 2011: chap 162.

10. Hambidge M (2000): Human Zinc Deficiency. Zinc and Health: Current Status and Future Directions. J Nutr; 130(5):1344S-9S.

11. Hamburg M (1985): Basic Statistics: A Modern Approach. Harcourt Brace Jovanovich (Publisher) 3rd edition. 193-8.

12. Hendler S and Rorvik D. (2008): PDR for Nutritional Supplements.2nd ed. Montvale: Physicians' Desk Reference Inc. 425-9.

13. Henwood MJ and Binkovitz L (2009): Update on pediatric bone health. The Journal of the American Osteopathic Association ; 109:5-12.

14. Hettiarachchi M, Liyanage $C$, Wickremasinghe $\mathrm{R}$ et al. (2008): The efficacy of micronutrient supplementation in reducing the prevalence of anemia and deficiencies of zinc and iron among adolescents in Sri Lanka. European Journal of Clinical Nutrition; 62, 856-65; doi:10.1038/ sj.ejcn.1602791; published online 16 May 2007.

15. International Zinc Nutrition Consultative Group (IZiNCG), Brown KH, Rivera JA et al. (2004): International Zinc Nutrition Consultative Group (IZiNCG) technical document \#1.Assessment of the risk of zinc deficiency in populations and options for its control". Food Nutr Bull; $25(1$ 2):S99-203.

16. Jensen PD (2004): Evaluation of iron overload. Br J Haematol; 124:697-711.

17. Kodama H. (2004): Trace Element Deficiency in Infants and Children: Clinical practice. JMAJ; 47(8): 376-81.

18. Lai, Y (2012): CCR5-targeted hematopoietic stem cell gene approaches for HIV disease: Current progress and future prospects. Current Stem Cell Research and Therapy; 7 (4):3107(8).

19. Madan N, Rusia U, Sikka $M$ et al. (2011):Developmental and neurophysiologic deficits in iron deficiency in children. Indian J Pediatr; 78(1):58-64. doi: 10.1007/s12098-0100192-0.

20. Nwosu BU and Lee MM (2008): Evaluation of short and tall stature in children. Am Fam Physician; 78(5):597-604.

21. Perrone L, Salerno M, Gialanella G et al.(1999): Long-term zinc and iron supplementation in children of short stature: effect of growth and on trace element content in tissues. J Trace Elem Med Biol ; 13(1-2):51-6.

22. Rivera JA, Hotz C, Gonzalez-Cossio $\mathrm{T}$ et al. (2003): The effect of micronutrient deficiencies on child growth: A review of results from community-based supplementation trials. J Nutr 133(11): 4010S-4020S.

23. Sachdev H, Gera T and Nestel P (2006) : Effect of iron supplementation on physical growth in children: systematic review of randomized controlled trials. Public Health Nutr ;9(7): 90420.

24. Sandstead HH (2003): Zinc is essential for brain development and function. The Journal of Trace Elements in Experimental Medicine ; 16(4): 165-73.

25. Sandström B (2001): Micronutrient Interactions: Effects on Absorption and Bioavailability. $\mathrm{Br} \mathrm{J}$ Nutr; 85 (2):S181-5.

26. Skrzypczak WF, Ożgo M, Lepczyński A et al. (2009): Dynamics of changes in iron concentration and total iron binding capacity in blood plasma of goat kids during their first month of life (Short Communication). Archiv Tierzucht; 52 (4): 419-24.

27. World Health Organization (1995): Physical status: the use and interpretation of anthropometry. WHO technical report series no. 854. Geneva.

28. Yamanishi H, Iyama S, Yamaguchi $\mathrm{Y}$ et al. (2003): Total iron-binding capacity calculated from serum transferrin concentration or serum iron concentration and unsaturated iron-binding capacity. Clin Chem; 49 (1): 175-8. 